[Podmore, V., Sauvao, L., \& Mapa, L. (2001). Transition to School: Current Issues and Pacific Islands Early Childhood Contexts. New Zealand Annual Review of Education, 10, 71-88]

\section{Transition to School: Current Issues and Pacific Islands Early Childhood Contexts}

\author{
VALERIE PODMORE, LE'AUTUlíilagi SAUVAO AND LiA \\ MAPA
}

\section{Abstract:}

This paper provides an overview of some current complexities related to transition to school from early childhood services in New Zealand. These include theoretical and policy matters concerning: continuity-discontinuity, diversity-standardisation, and ease of transition. We then highlight some key issues arising from a study, reported during the year under review, on transition to school from Pacific Islands early childhood services. Drawing on the main emergent themes, we comment on methodological implications and culturally preferred practices, and identify some concerns and challenges.

$\mathrm{D}$ uring the year under review, the New Zealand government had pledged to invest in increasing participation in early childhood education. In July 2000, the Minister of Education reiterated that: "increasing participation in quality early childhood education is one of our key objectives for the early childhood sector" (Mallard, 2000, p. 1). A July budget update contributed by the Ministry of Social Policy for publication in Pitopito Korero included summary information for practitioners about part of the Government Budget package, under these headings:

- Increased Funding for the General Pool of the Discretionary Grants Scheme (Total $\$ 2.200$ million over 4 years);

- Increased Funding for the Pacific Pool of the Discretionary Grants Scheme (Total $\$ 7.250$ million over 4 years);

- Extend Pre-and Post-licensing Support and Administrative Upskilling for Pacific ECE Services (Total $\$ 0.340$ million over 4 years);
- ECE Planning and Forecasting (Total \$0.400 million over 2 years only);

- Adjustment to Early Childhood Education SessionalFunding(Total $\$ 36.393$ million over 4 years);

- Development of an Early Childhood Education Strategic Plan (Total $\$ 0.150$ million over 2 years);

- Measures to Recruit Maori and Pacific Peoples to Early Childhood Teaching (Total \$1.0 million over 2 years only);

- Upgrading to Diploma of Teaching (ECE) as Benchmark Qualification (Total $\$ 1.841$ million over 4 years);

- Equity Funding (\$0.100 million in 2000/01 only);

- Equity Funding Working Party (\$0.060 million in 2000/01 only);

- Additional Support for At-Risk Community based ECE Services;

- Funding for High Special Needs Children in the Early Childhood Sector (Total $\$ 4.288$ million over 4 years).

(Ministry of Education, 2000b, pp. 1-2)

Concomitantly, there was continued interest in transition issues for the increased numbers of young children participating in early childhood services in New Zealand. The overall increase in enrolments in early childhood services was 4.3 percent between 1990 (118,365 children) and July $1999(172,160) .^{1}$ The July 1999 statistics also show that slightly more than 90 percent of 3-year-olds, and 99.5 per cent of 4 -year-olds were enrolled in at least one early childhood service that year (Ministry of Education, 2000a, p. 13). These rates may be inflated by a number of children being enrolled concurrently in more than one type of service (Ministry of Education, 2001). However, the data suggest that most children entering primary school are making a transition from an early childhood service to school.

For many young children, there are a number of points or stages of educational transition, including transition from home to an early childhood service, transition across the early childhood services themselves (given the high concurrent and sequential use of several early childhood services for individual children), and transition to school. Recent New Zealand research on young children's transition is addressing both transition from home to early childhood services (Dalli, $1999,2000)$ and transition from an early childhood service to primary school (Peters, 2000a, 2000b; MacDonald, McNaughton, Tamarua Turoa, \& Phillips, 1999; McNaughton, 1998; Robinson, Timperley, \& Bullard, 2001; Sauvao, 1999; Sauvao, Mapa, \& Podmore, 2000; Wolfgramm, 1992). 
Current Conceptualisation: Theories, Paradigms, and Issues

\section{Theoretical underpinnings}

Theories of children's learning and development underpin a number of studies focused on the learning experiences of children moving from early childhood to school settings. Several studies pertaining to transition have drawn on Bronfenbrenner's ecological a pproach (1979).

Bronfenbrenner described contexts for development, and his ecological model draws attention to the importance of home, school, and community as contexts for learning and development. This approach underlies a range of studies concerned with continuities and discontinuities across contexts.

Vygotsky's (1978) theory is also prominent in recent research on transition to school in New Zealand (MacDonald et al., 1999; Norris, 1999; Peters, 2000b; Sauvao, Mapa, \& Podmore, 2000). Vygotsky saw children's learning as being guided, modelled, and structured by adults in a process Bruner (1985) describes as "scaffolding". Vygotsky's perspectives emphasise the contexts of learning, social interaction, and the influence on children's learning of an understanding of the culture(s) which surround them:

Every function in the child's cultural development appears twice: first, on the social level, and later, on the individual level; first,

between people (interpsychological) and then inside the child (intrapsychological). (Vygotsky, 1978, p. 57)

According to Vygotsky, children's learning is most appropriately achieved in the "zone of proximal development". This is the area slightly beyond the level of the child's independent competence, where learning may take place by the child being guided in the presence of more competent others.

Within and beyond Vygotsky and Bronfenbrenner's perspectives, Māori theoretical perspectives on development provide further theoretical frameworks for interpretation of these and related issues (MacFarlane, 2000; Royal Tangaere, 1997).

Transition to school studies take on different perspectives, including a "parent's" perspective, a "teacher's" perspective, and/or a "child's" perspective (Mapa, Podmore, \& Mara, 1998). Numerous studies provide suggestions for successful transition from home and early childhood settings to primary school.

\section{Diversity, standardisation, and separation}

One of the complexities concerning transition is the degree to which diversity is accommodated both in early childhood education contexts and in primary schools. As Helen May proposes, there were contradictory processes and discourses in evidence during the last decade of early childhood policy development in Aotearoa. Among the processes May mapped out, "diversity $\Longleftrightarrow$ standardisation", and "seamlessness $\Leftarrow \Rightarrow$ separation" are particularly pertinent to transition issues under scrutiny here (May, 2000, p. 129).

Policy developments in the early childhood sector have included initiatives to recognise diversity in regard to Pacific languages and cultures. There has been an accompanying trend towards standardisation of quality, through licensing and chartering of increased numbers of Pacific Islands early childhood centres, for example (Mara, 1998b).

When considering the "seamlessness $\Leftarrow \Rightarrow$ separation" processes in New Zealand, "separation" is evident in early childhood curriculum and in teacher education. From the perspective of young children's learning and development, these are "positives", as already pointed out by May (2000). Aspects of curriculum and teacher education in turn impinge upon children's experiences of transition to school.

\section{Continuity, discontinuity, and easing transition}

A number of useful resources have been provided with the intention of easing children's transition to school (Briggs \& Potter, 1990; Renwick, $1984,1997)$. There is clearly concern about continuity and discontinuity of children's experiences (Margetts, 1994, 1997). Several resources and research studies point to the need to relate transition strategies and policies to children's perspectives and expectations.

Currently, "continuity-discontinuity" tends to be viewed as a complex continuum (Peters, 1999, 2000a; Robinson et al., 2001; Sánchez \& Thorp, 1998). McNaughton (1998) notes the importance for children of matching their experiences across home and formal educational settings, and of "sharing understandings about activities and learning and teaching" across settings (p. 35). Drawing on Vygotsky's perspectives on contexts of development and Bruner's work on scaffolding, Sánchez and Thorp (1998) and Peters (2000a) contend that continuity has multiple meanings in the context of transition. Peters' research suggests that "what is important is not maintaining complete continuity, but to avoid creating discontinuity that is beyond the child's ability to negotiate" (2000a, p. 21). Robinson et al. concur that the 
concept of continuity is complex, and propose that "some degree of discontinuity is inevitable, and may be desirable if it provides the impetus for developmental change" (2001, p. 95).

\section{Issues from Pacific Islands Early Childhood Contexts}

At seminars and meetings in 1997-98, the New Zealand Council for Educational Research (NZCER) was informed that there was a need to enhance existing knowledge about the transition of children from Pacific Islands services to primary school. Subsequently, a small-scale, exploratory study was designed to include families from each of five ethnic groups (Cook Islands, Niue, Samoan, Tokelauan, and Tongan). The intention was to provide an account of the experiences of children, parents, and teachers, focusing on language and other aspects of children's move from Pacific Islands early childhood centres into English-language primary schools. The study on transition to school from Pacific Islands early childhood services was completed during the year under review, and this section synthesises issues arising from that research (Sauvao, Mapa, \& Podmore, 2000).

Five research questions were posed, focused on children's transition from Pacific Islands early childhood centres to schools:

- What are the similarities and differences between the contexts of home, school, and early childhood settings?

- What are the aspirations, expectations, and views of parents, teachers, and children of these contexts?

- How well do children make the transition between the contexts (as defined by the children themselves)?

- How can the information collected in this study assist teachers and parents to facilitate transition across the three contexts? and, in particular;

- How do schools continue to assist and support the home languages and cultures of Pacific Islands children starting primary school? What is the language policy of the school (as stated in the charter)?

The research processes included conducting interviews using culturally appropriate approaches. The results of the interviews focused primarily on participants' accounts, and included the voices of 27 children, their parents, and their early childhood and primary school teachers. There was also an analysis of the content of the charters of the 19 participating primary schools. Findings from the interviews with children, parents, early childhood teachers, and school teachers addressed the five research questions. The interviews yielded considerable information about young Pacific Islands children's experiences of different contexts. Contexts included their homes, their early childhood centres or programmes, and schools. Several key issues emerged from a synthesis of the literature reviewed, relevant demographic data, and from the interview findings and charter analyses.

\section{Culturally appropriate methodologies}

The research offers a methodological model for interviews with children, parents, and other participants from Cook Islands, Niue, Samoan, Tokelauan, and Tongan communities. Representatives of the Pacific Islands early childhood national organisations and their nominated field researchers participated, providing links between the research and the five communities represented in it. Consistent with previous research approaches among Samoan participants, respect and consensus were deemed important considerations (Sauvao, 1999; Tupuola, 1993). Interviewers from each of the five different Pacific Islands groups endeavoured to ensure that the research approaches developed were culturally appropriate for participants from each community. Members of the project advisory committee pointed out that this research appears to be the first to document the interview process for, and by, members of all five ethnic communities, and believed that the research extends current knowledge on interviewing 5-year-old children about their experiences.

Ethical considerations, research instruments, and procedures were all scrutinised for cultural appropriateness. The five interviewers contributed to developing approaches to consent and confidentiality that were culturally relevant through all phases of the research, and consistent with the ethics statements of the New Zealand Council for Educational Research (1998) and the New Zealand Association for Research in Education (1999). All interviewers, and members of the advisory committee, had the opportunity to check the draft interview schedules for cultural a ppropriateness. Each interviewer aimed to adopt culturally sensitive procedures when interviewing family members. The participants made clear requests for a summary of the findings of the research, highlighting the relevance of providing feedback in an appropriately accessible form.

The inclusion of interviewers who had links to Pacific Islands communities added value to the study, as this helped set up comfortable situations, ensured cultural sensitivity, reduced language barriers, and contributed to responsive communication of the research 
findings. The research process provided training for interviewers who were not necessarily familiar with research methods, but had close, long-standing connections with their communities. McNaughton, Wolfgramm, and Afeaki (1996) support the inclusion of training of Pacific researchers as an integral part of educational research contracts. The importance of the training component of this research affirms and extends their comments.

\section{Key Issues}

\section{Language and cultural continuity}

The apparent number of Pacific Islands children enrolled in early childhood services increased by 80.9 percent between 1990 and 2000, and there was an increase in the number of Pacific Islands children enrolled in "Pacific Islands language groups" between 1990 and 1994. From 1994 to 1998, there was a marked increase in enrolment at "Pacific Islands childcare centres", reflecting a trend towards licensing and chartering of the groups. One pertinent question arising from this study concerns the extent to which children will retain the languages and cultural practices fostered within these early childhood services as they progress through school.

Bale (1993) examined the role of language in readiness for school and asserted that each child's behaviour revealed different interests and different levels of communication. According to Bale, memories of positive language experience gave children feelings of confidence and high self-esteem, competency and control, and promoted a willingness to stay involved. Stipek's (1988) and Benton's (1995) research also supports these conclusions.

Parents participating in this study articulated concerns about the maintenance of their children's Pacific Islands language and culture. There was also a tendency for parents to report that they did not know what the language policy was at the school their child attended.

\section{Funding for language provision in schools}

Data on the 19 schools' decile ratings showed that a disproportionate number of children attended schools in the lowest socio-economic stratum. The student population at 9 of the 19 schools included more than 30 percent who identified as Pacific Islanders. Interviews with the school teachers indicate that 2 of the 19 schools provided teaching of Pacific Islands children's ethnic languages. The remaining 17 schools either chose to have Polynesian clubs one hour a week or to integrate
Pacific studies once a month or term with other curriculum subjects.

Having insufficient funding seems to be the cause of the non-provision of Pacific Islands languages in some schools. This is also supported by Sauvao's (1999) interviews, which showed that principals usually gave administrative reasons as to why language continuity could not be fully achieved in their programme. It appears that under-resourced schools will be more likely to encounter barriers to furthering language activities of graduates from Pacific Islands early childhood services.

\section{Successful partnership between home and school}

The interviews re-affirmed the relevance of home-school-community relationships to parents, children, and teachers. Interview data suggest that continuing communications regarding progress of students in the three contexts, and regular contact between the early childhood centres and the primary schools, are likely to assist the transition process.

These findings support the need for continuing development and uptake of models to enhance the connections among schools and Pacific Islands early childhood services, families, and communities. One success model for this study is the Pacific Islands School-Parent-Community Liaison Project, reported on by Diane Mara (1998a). Another is the Strengthening Education project in Mangere and Otara on early literacy (MacDonald et al.,1999; Robinson et al., 2001).

\section{Expectations of teachers and parents}

The early childhood teachers interviewed expected children to have literacy skills and to be able to write their own names when starting school. They were also concerned about the lack of continuity of ethnic languages when children moved on to primary school.

Primary school teachers generally expected children to come with social skills, language and culture, mathematical and literacy skills, respect, and basicknowledge of English. However, some teachers stated that they would accept children as they were, and that children need to be confident about communicating with peers and teachers. Findings by Renwick suggest that teachers are likely to emphasise that "the main thing is the child's attitude to new experiences" (1997, p. 44). This includes being curious and keen to learn.

The parents' views showed some similarity to those of the teachers. They wanted the children to learn literacy, respect, language, culture, and mathematical concepts, and to help each other in the home. They 
expected the schools to offer intellectual challenges for their children, and to assist in the maintenance of their language and culture. Parents also expected the schools to address any concerns about their children immediately. Some parents expressed concern about the uncomfortable transition for children who have limited English. However, the majority of parents reported that their children had no problems when they first started school. Other children settled well because they had siblings and friends at the same school. The parents generally chose the schools for their children based on the geographical situation, reputation of the school, teaching methods, or - for some parents - because of their religion.

\section{Bullying}

This topic was not planned as a focus for the interview questions. However, when children were asked what they disliked about school, $11(41 \%)$ specified being hurt or bullied. This suggests discontinuities and differences across contexts, because the children did not mention being bullied at the early childhood centres they attended. Several parents specified that physical aggression and fighting were difficulties experienced at the time of starting school. This caused fearful attitudes among some young children when they first started primary school.

Bullying is clearly recognised as a current problem in schools (Blatchford, 1989; Byrne, 1994; Smith \& Sharp, 1994a, 1994b; Sullivan, $2000 \mathrm{a}, 2000 \mathrm{~b}$ ). Blatchford carried out research in British primary schools to address this issue. His suggested improvements included having more adult supervision, and making separate arrangements for the youngest children in school.

A survey about children bullying and their experience of being bullied was conducted by a Norwegian psychologist, Dan Olweus, in a school north of Wellington. Olweus found that 57 percent of children surveyed were ambivalent or didn't like school much, and 144 children $(58 \%)$ said they had been bullied. Only 27 percent felt comfortable about approaching a teacher when they were bullied, and much bullying happened in the classroom or toilets rather than out of school time (Matheson, 1997; see also, Olweus, 1993).

In a report on NZCER's competent children study, Wylie, Thompson, and Lythe (1999) found that the parents of children aged 8 years also expressed concerns about behaviours associated with bullying such as teasing, unkindness, rudeness to parents, fighting, or tantrums. Further, Maxwell and Carrol-Lind's (1997) study about the impact of bullying on year 12 (forms 1 and 2) children shows bullying to be a common and hurtful experience.

More recently, Sullivan $(2000 \mathrm{~b})$ has documented successful antibullying strategies, and advocates whole-school approaches to counteract bullying. Sullivan defines bullying as being about "the abuse of power", recommends that teachers become knowledgeable about "the dynamics of (social) interactions," and identifies specific forms of bullying (including "racist bullying") (Sullivan, 2000a, p. 40).

The findings from the present study suggest that young children at transition points may be vulnerable to "abuse of power" by other children, but there is no evidence as to whether racist bullying occurred. It is assumed that schools have rules on bullying and swearing, but several parents appeared concerned as to whether these behaviours are regularly monitored.

\section{Curriculum continuity}

The recommendations of parents and teachers interviewed in this study suggest that it is advisable for early childhood centres and schools to liaise and consult about curricula and policy documents. Documents for joint consultation could include Te Whāriki (the New Zealand early childhood curriculum - Ministry of Education, 1996), the DOPs (Desirable Objectives and Practices), Ta'iala (Samoan Language Curriculum), and the New Zealand Curriculum Framework.

The school teachers interviewed expressed the need for parents, children, and teachers to experience regular contact between early childhood centres and primary schools. This would allow for curriculum observations, and would enable children to meet their new teachers and become familiar with new routines and the environment.

Bradby (1995) supported this by using the situation at Pleasant Street School in Ballarat, Australia, to illustrate the key elements of a successful transition programme. The key elements include networking of early childhood teachers, discussion groups, organising kindergarten weeks, family gatherings, and open days. The underlying philosophy in identifying these key elements was the view that the school should be ready for the child, not vice versa.

\section{Literacy}

Research by McNaughton and colleagues has described how samples of Pacific Islands children engage in reading and writing experiences prior to school entry or in the home (McNaughton, Parr, \& Smith, 
undated). In the present study, 19 (70\%) of the parents wanted children to learn literacy skills at home, and 9 out of 11 early childhood teachers wanted the children to learn literacy skills in the early childhood centre, before attending school. Thirteen (59\%) of 22 teachers expected children to come with literacy experience, for example, love of books, handling of books, identification of letters, writing, and recognition of names.

The children were asked about what they do when "trying to read something, but it is hard." Compared with data from NZCER's Competent Children study (Wylie \& Thompson, 1998), the findings from this study suggest a greater tendency among the Pacific Islands children to seek assistance from people. For example, in comparison with 52 percent of the children in this study, only 27 percent of children in the Competent Children study responded that they would request help from the teacher if they encountered difficulties when reading. This suggests that teachers of Pacific Islands children may be asked for help, and that seeking their help is likely to be a positive strategy for the children to adopt.

\section{Teacher education}

The teachers in the early childhood centres and primary schools, when asked about the extent to which schools should support the home languages and cultures of Pacific Islands children, suggested that early childhood centres and primary schools should provide professional development for teachers. This would enable them to teach children about the Pacific Islands languages and cultures.

As pointed out by Coxon and Mara (2000), there remains scope for teachers of Pacific students to be informed about "Pacific concepts associated with valued knowledge, teaching and learning" (p. 179). Coxon and Mara give several examples as useful starting points, including Konai Helu-Thaman's use of metaphor to "provide insights into Tongan values of learning, knowledge, and wisdom" (p. 179).

Duncan (1993) supports the need for trained early childhood teachers. She found under-resourcing, poor pay, and low levels of training for many early child hood education workers. Further, drawing on research studies, Carr, May, and Podmore contend that early childhood teacher qualifications, training, and professional development are required for the effective implementation "of a national curriculum to make a positive difference for children" (2000, p. 2). This view is substantiated by recent reviews of international research (Podmore \& Meade with Kerslake Hendricks, 2000).
According to Renwick, "all children are different, and teachers are trained to deal with new entrants as they are when they start school, no matter what skills they have already" (1997, p. 44). For primary school teachers, teacher education about responding to children's current level of understanding is a critical factor in transition. This is consistent with theoretical perspectives already outlined. Teacher education that includes Vygotsky's theoretical perspectives concerning the "zone of proximal development" will assist teachers to foster and guide young children's thinking and learning.

\section{Pacific Islands representation in schools and education}

The findings from the interviews with parents and teachers suggest a need for more Pacific Islands teachers, and for Pacific Islands community involvement in schools. Seven of the 11 early childhood teachers expressed concern about children's transition to school, citing the non-continuation of their mother tongue in school. Parents of almost all the children ( 25 of the 27 ) stated that the primary school did not teach their child's Pacific Island language. However, to provide teaching in this area, more Pacific Islands teachers and community people would be needed.

Similarly Dickie (2000) has observed that there are community demands for more Pacific nations teachers and for more teaching in Pacific languages. However, he notes that these demands are not being met because there is a decline in current enrolments of Pacific nations students in teacher education courses. On the basis of his interviews with 21 Pacific nations teacher-education students in Wellington, Dickie has outlined a set of preferred support strategies for Pacific nations students.

The advisory committee for this research project also suggested, on the basis of the findings, that there should be more involvement of Pacific Islands communities in schools. Furthermore, it recommended that, for equity purposes, representation of Pacific Islands people is needed in management, policy, and research areas. In this way, the educational, economic, political, and social needs and the concerns of Pacific Islands people might be further addressed.

\section{Concluding Comments}

During the last decade in New Zealand, participation in the Pacific Islands early childhood centres has clearly increased. Current complexities related to transition to school from early childhood services 
include theoretical and policy matters related to:

- continuity $\Longleftrightarrow$ discontinuity;

- diversity $\Longleftrightarrow \Rightarrow$ standardisation; and

- ease of transition.

These complexities and concerns are evident in recent research findings on transition to school from Pacific Islands early childhood services. Continuity $\Longleftrightarrow$ discontinuity and diversity $\Longleftrightarrow \Rightarrow$ standardisation underlie several key issues identified: language and cultural continuity; partnership between home, early childhood services, and school; expectations of teachers and parents; bullying; curriculum continuity; literacy; teacher education; and Pacific Islands representation in schools and education

\section{Note}

1. However, between July 1998 and July 1999 the growth rate slowed to 0.6 per cent, reflecting a parallel trend in the birth rate.

\section{References}

Bale, M. (1993). Empowering parents and caregivers as language facilitators. Toronto: The Hanan Centre.

Benton, R. (1995). Polynesian languages on the information highway. In M. Warschauer (Ed.), Virtual connections: Online activities $\mathcal{E}$ projects for networking language learners (pp. 173-177). Manoa: University of Hawai'i at Manoa, Second Language Teaching \& Curriculum Center.

Blatchford, P. (1989). Playtime in the primary school: Problems and improvements. Windsor, England: NFER-Nelson.

Bradby, J. (1995). Transition and why it matters at Pleasant Street. Paper presented at the Early Years of Schooling Conference, Victoria, Australia.

Bronfenbrenner, U. (1979). The ecology of human development. Cambridge: Harvard University Press.

Bruner, J. (1985). Vygotsky: A historical and conceptual perspective. In J. V. Wertsch (Ed.), Culture, communication, and cognition: Vygotskian perspectives (pp. 21-35). Cambridge: Cambridge University Press.

Byrne, B. (1994). Coping with bullying in schools. London: Cassell.
Carr, M., May, H., \& Podmore, V. N., with Cubey, P., Hatherly, A., \& Macartney, B. (2000). Learning and teaching stories: Action research on evaluation in early childhood. Final report delivered to the Ministry of Education. Wellington: New Zealand Council for Educational Research.

Coxon, E., \& Mara, D. (2000). Education policies for Pacific Nations peoples. In J. Marshall, E. Coxon, K. Jenkins, \& A. Jones (Eds.), Politics, policy, pedagogy: Education in Aotearoa/New Zealand (pp. 157-184). Palmerston North: Dunmore Press.

Dalli, C. (1999). Starting childcare before three: Narratives of experience from a tri-partite focus. Unpublished PhD thesis, Victoria University of Wellington.

Dalli, C. (2000). Beyond separation: Starting childcare before three. Childrenz Issues, 4(1), 21-26, 45.

Dickie, J. (2000). Pacific nations students in primary teacher training: Investigating their learning needs. set, 2, 11-14.

Duncan, H. (1993). Government's role in early childhood and the first years of school. In V. Podmore (Ed.), What is government's role in early childhood education? Papers presented at the 1993 NZCER invitational seminar (pp. 82-89). Wellington: New Zealand Council for Educational Research.

MacDonald, S., McNaughton, S., Tamarua Turoa, L., \& Phillips, G. (1999, November/December). Early childhood settings as sites for enhancing children's narratives. Paper presented at the joint AARE-NZARE conference, Melbourne, Australia.

MacFarlane, A. (2000, December). The education of Māori (Panel). Keynote panel symposium at the Annual Conference of the New Zealand Association for Research in Education, University of Waikato, Hamilton.

McNaughton, S. (1995). Patterns of emergent literacy: Process of development and transition. Auckland: Oxford University Press.

McNaughton, S. (1998). Activating developmental processes over the transition to school. Childrenz Issues, 2(1), 34-38

McNaughton, S., Parr, J., \& Smith, L. T. (n. d.). Process of teaching and learning in literacy - Writing. Research project No: ER35/335, final report to the Ministry of Education, Wellington, New Zealand. 
McNaughton, S., Wolfgramm, E., \& Afeaki, V. (1996). Reading strategies for Tongan preschoolers. Paper prepared for the Ministry of Education, Wellington, New Zealand.

Mallard, Hon. T. (2000, July 11). Speech notes for address to NZEI Te Riu Roa Early Childhood Millennium Conference, Victoria University of Wellington.

Mapa, L., Podmore, V. N., \& Mara, D. (1998). Literature review for project "Transition to school from Pacific Islands Early Childhood Services". Unpublished paper. Wellington: New Zealand Council for Educational Research.

Mara, D. (1998a). Pacific Islands school-parent-community liaison project: An independent evaluation report. Wellington: New Zealand Council for Educational Research, and Ministry of Education.

Mara, D. (1998b). Progress towards licensing and chartering Pacific Islands early childhood centres in New Zealand. Wellington: New Zealand Council for Educational Research.

Margetts, K. (1994). Children's adjustment to the first year of school. Unpublished master's thesis, University of Melbourne.

Margetts, K. (1997). Factors impacting on children's adjustment to the first year of school. Early Childhood Folio, 3: A collection of recent research, pp. 53-56. Wellington: New Zealand Council for Educational Research.

Matheson, D. (1997, March 19). Happiness is a safe school. New Zealand Education Review, 9-10.

Maxwell, G., \& Carrol-Lind, J. (1997). The impact of bullying on children. Wellington: Office of the Commissioner for Children.

Ministry of Education. (1996). Te Whāriki: He Whāriki Mātauranga: Early childhood curriculum. Wellington: Learning Media.

Ministry of Education (2000, May 22). Early childhood roll growth slows. New Zealand Education Gazette, 13. Wellington: Ministry of Education.

Ministry of Education (2000, June). Pitopito Korero, No. 23. Wellington: Ministry of Education.

Ministry of Education (2001). Early childhood statistics: July 1999. $<$ www.minedu.govt.nz >
May, H. (2000). ece2000@aotearoa.nz: Mapping the landscape of "the century of the child". New Zealand Annual Review of Education, 9, 117-132.

New Zealand Association for Research in Education. (1999). Ethical guidelines of the association: New Zealand Association for Research in Education. NZARE membership directory. (pp. 7-8). NZARE.

New Zealand Council for Educational Research. (1998). Ethical statement. Wellington: NZCER.

Olweus, D. (1993). Bullying in schools: What we know and what we can do. Oxford: Blackwell.

Peters, S. (1999, April). Continuity and discontinuity: Issues for parents and teachers seeking to enhance children's transition to school. Paper presented at "Sharing Research in Early Childhood Education", the Third Warwick International Early Years Conference, University of Warwick, Coventry, England.

Peters, S. (2000a, August/September). Multiple perspectives on continuity in early learning and the transition to school. Paper presented at "Complexity, diversity and multiple perspectives in early childhood", the Tenth European Early Childhood Education Research Association Conference, University of London, London.

Peters, S. (2000b). "I didn't expect that I would get tons of friends... more each day": Children's experiences of friendship during the transition to school. Paper presented at the annual conference of the New Zealand Association for Research in Education, University of Waikato, Hamilton, December.

Podmore, V. N., \& Meade, A., with Kerslake Hendricks, A. (2000). Aspects of quality in early childhood education. Literature Review Series. Wellington: New Zealand Council for Educational Research.

Renwick, M. (1984). To school at five: The transition from home or preschool to school. Wellington: New Zealand Council for Educational Research.

Renwick, M. (1997). Starting school: A guide for parents and caregivers. Wellington: New Zealand Council for Educational Research.

Robinson, V., Timperley, H., \& Bullard, T. (2001). Strengthening education in Mangere and Otara evaluation: Second evaluation report. Report to the Ministry of Education. Wellington: Research Division, Ministry of Education. 
Royal Tangaere, A. (1997). Learning Māori together: Kohanga reo and home. Wellington: New Zealand Council for Educational Research.

Sánchez, S. Y., \& Thorp, E. K. (1998). Discovering meanings of continuity: Implications for the infant/family field. Zero to Three, 18(6), 3-6.

Sauvao, L. M. F. (1999). Transition from a'oga amata to school: Case studies in the Wellington region. Unpublished Master's thesis, Victoria University of Wellington.

Sauvao, L., Mapa, L., \& Podmore, V. N. (2000). Transition to school from Pacific Islands early childhood centres. Wellington: New Zealand Council for Educational Research.

Smith, P. K., \& Sharp, S. (1994a). School bullying: Insights and perspectives. London: Routledge.

Smith, P. K. \& Sharp, S. (1994b). Tackling bullying in your school: A practical guide for teachers. London: Routledge.

Stipek, D. (1988). Motivation to learn: From theory to practice. Englewood Cliffs, New Jersey: Prentice-Hall.

Sullivan, K. (2000a). Bullying in schools: Issues for New Zealand teachers. set, 2, 39-43.

Sullivan, K. (2000b). The anti-bullying handbook. Auckland: Oxford University Press.

Tupuola, A-M. (1994). Raising research consciousness the Fa' a Samoa Way. New Zealand Annual Review of Education, 3, 175-189.

Vygotsky, L. S. (1978). Mind and society: The development of higher mental processes. Cambridge, MA: Harvard University Press.

Wolfgramm, E. A. (Ed.). (1992). An assessment of the effects of the home-based programme on children's transition from home to classroom settings. Wellington: Anau Ako Pasifika.

Wylie, C., \& Thompson, J. (1998). Competent children at 6: Families and early education (Vol. 1). Wellington: New Zealand Council for Educational Research.

Wylie, C., Thompson, J., \& Lythe, C. (1999). Competent Children at 8: Families, early education, and schools. Wellington: New Zealand Council for Educational Research.

\section{The authors}

Dr Val Podmore lectures in early childhood education at the Institute for Early Childhood Studies, Victoria University of Wellington and Wellington College of Education. She was formerly a senior researcher and research group leader at the New Zealand Council for Educational Research.

Le'autuli'ilagi Sauvao is the Pacific Islands national manager (Ta'ita'i Pasefika) at Early Childhood Development. She was formerly the fieldwork co-ordinator of the Pacific Islands Transition to School project at the New Zealand Council for Educational Research.

Lia Mapa is a research assistant at the New Zealand Council for Educational Research

\section{Acknowledgements}

The second section of this paper is based on the project, "Transition to School from Pacific Islands early childhood services" (Sauvao, Mapa, \& Podmore, 2000). We acknowledge warmly the co-operation of the parents, children, early childhood teachers, school teachers, and school principals in that project. We acknowledge and respect the contributions of other members of the interview team: Tapaeru Tereora (Cook Islands sample); Suria Timoteo (Tokelauan sample); Ina Mora (Niue sample); Taniela Vao (translation, Tongan group). Representatives of the Pacific Islands early childhood organisations, and Diane Mara (1998 researcher) made valuable contributions to planning the study, and we are grateful for the contributions of the members of the advisory committee. That project was funded through the Ministry of Education's purchase agreement with NZCER. 